\title{
A new home for the world mathematics: The grand opening of Tsinghua Sanya International Mathematics Forum
}

\author{
by Lizhen $\mathrm{Ji}^{*}$
}

\section{Introduction}

Zhuang Zi said: A phoenix starts from the South Sea and flies towards the North Sea, and it will only stop and rest on a $\mathrm{Wu}$-Tong tree.

How about a mathematical phoenix? Maybe a better resting place for it is the Phoenix Mountain near the South Sea!

On December 18, 2013, the largest mathematics conference center in the world was opened on the top of the Phoenix Mountain. It will be a permanent forum for mathematics and related subjects such as physics, economics and engineering.

On that sunny and warm day, I had the good fortune to witness this historical event together with near 300 hundreds of people from the world. They were the leaders of Tsinghua University and the local government, mathematicians and scientists representing many major universities and mathematics centers around the world, and other VIP.

It is rare to rub shoulders with so many distinguished people at one common place and at the same time. The following is a record of the first day at the Sanya Forum.

\section{The Long Staircase and a Stone Carving}

When you arrive at the main building of the Sanya Forum, an imposing round building is looking down

\footnotetext{
* Department of Mathematics, University of Michigan E-mail: lji@umich.edu
}

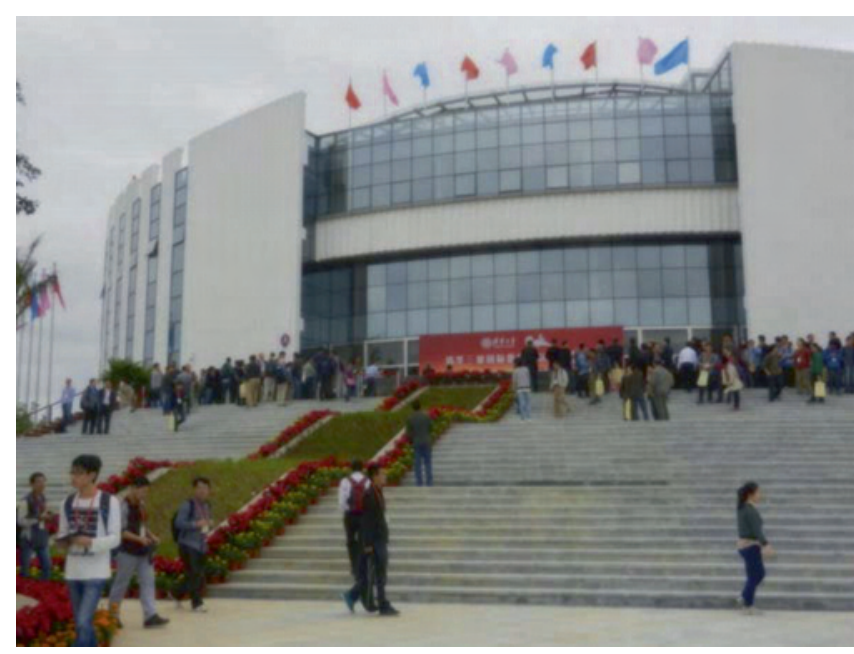

Figure 1. The long staircase leading to the main building.

upon you. A long flight of stairs will lead you to the gate of the building, and on the way up you could think of what to talk or what to expect to hear.

Here are some pictures of the main building (Fig. 1).

Maybe before going up, you could take a look at writings on a big stone on the left. It is a poem composed by Professor Yau especially for the Sanya Forum (Fig. 2). 


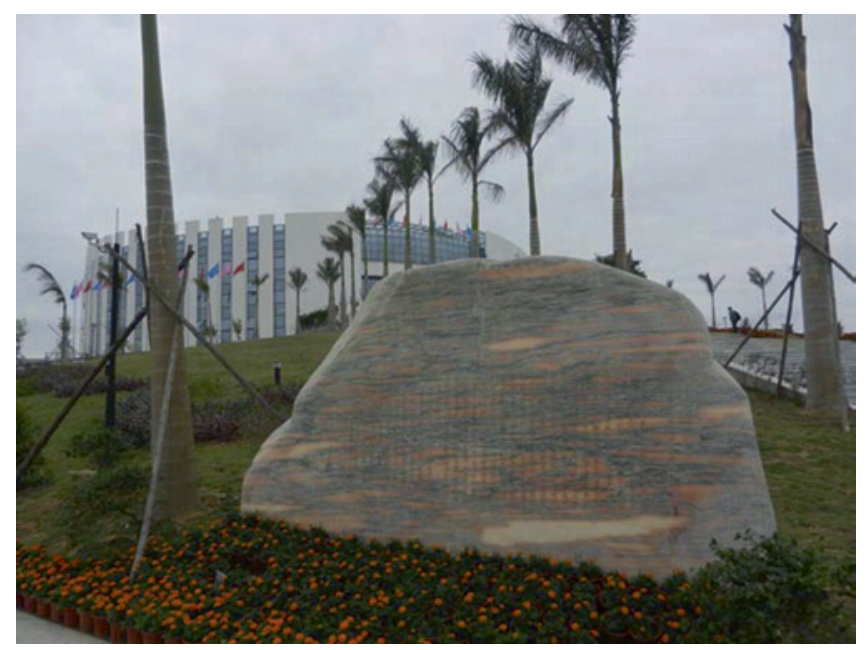

Figure 2. The stone with the Poem of Prof. Yau carved on it.

\section{On the Tsinghua Sanya International Mathematics Forum by Shing-Tung Yau}

The virtuous find pleasure in hills; the wise find pleasure in water. High as the mountain and long as the river, this is the style of a scholar. Broad as the sky and wide as the earth, this is the heart of a philosopher.

Man's greatest thoughts are inspired by Mother Nature. So it has been from the time of the ancients, and the feeling is always the same. For this reason, Qi opened boulevards and Chu refurbished the Palace of the Orchid Terrace. The scholars Mencius, Xun Qin, Zou Yan and Qupin galloped in the North and in the South; both their ideas and their writings were rich and splendid. The atmosphere of the Ji-xia Institute was inspiring and the ideology of the Lanling was nourishing. The great historian Sima Qian studied the relation between heaven and man; his book was hidden in a famous mountain. The master Zhu Xi explored the classics; he lectured at the Cave of the White Hart. For thousands of years this principle has been spreading. How can it be without merit?

Today, with the blending of Eastern and Western culture, both literature and sciences are blooming. The study of physics reveals the mystery of Nature and the study of mathematics is widely appreciated. Mathematicians find profound solutions to conjectures that stun the world; they create new theories whose impact is long lasting. Therefore, mathematical forums were set up at the snow ridges of North America, and mathematical institutes were planted in the deep forests of Europe. Scenery can affect people; it sways their temperament and gradually it materializes their thoughts. It makes their writing beautiful and their thinking deep.
So shall the province of Hainan, the Pearl Island, where satellites were once launched and the famous five ministers' once chanted their bardic song. As the star of wisdom shone at Hainan, the government officials initiated the call for a mathematical forum at Sanya. The response was heard from hundreds of scholars. Traveling around the island, from north to south, scholars at Tsinghua University were actively engaged in setting up this institute. Their courageous, pioneer spirit has led them after many difficulties to a road of dreams. For their hard work, a magnificent building stands on the ridge of the Pearl Island, and one believes that elites from all over the world are gathering there. Diligent students and renowned scholars are tranquil in the pursuit of knowledge; calmly and humbly they seek excellence in their research. Though far away from the lovely Near Spring Garden at Tsinghua, the beautiful landscape at Sanya may bring them joy. With outstanding academics and talented students from around the world, the pearl of academic developments will shine its light at Sanya. This great achievement is not only the virtuous output of its founders but also the sincere hope of the scholars of China! The words say:

Five-Finger is the mountain, Phoenix is the ridge; Gaze towards the center, and protect the south, The four seasons are mild, coconuts sway and bananas scent; Phoenixes are at home in the land of treasure, and jade is rich at the mountain peak.

Mathematics rules the world, and frames the universe. Splendid theories are established, and great mathematicians are numerous. Learn from others, or lecture in hall theaters; Activities carry on, and mathematics prospers.

Follow the masters, and learn their scholarship; Admire their perfection and integrity, and appreciate their greatness and rigidity. Enjoy meeting distant friends and traveling around the four seas. Exchange great thoughts and fantastic ideas. Students should learn from the elites and react constantly; Work hard without regret, love theories without abandon. Knowledge is infinite; strategic learning can get you through! Appreciate the beauty of the universe and analyze the principle of things; examine the history and understand the details. Discriminate clearly and react carefully, and the truth will be more illuminating.

Working toward the long-cherished goal without falling slack, the descendants of China should strive to go further.

Is Prof. Yau a mathematician or a poet? The president of UC Santa Barbara, Mr. Yang, was asked this question and his answer was that "Prof. Yau is both!". Prof. Yau's poem was rendered by a famous calligrapher. 


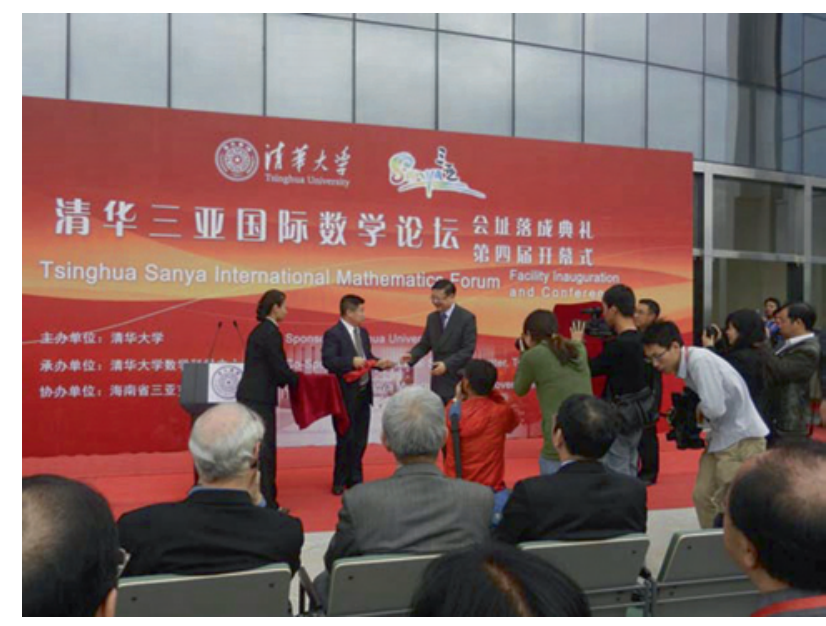

Figure 3. The key of the main building was handed to the President of Tsinghua University.

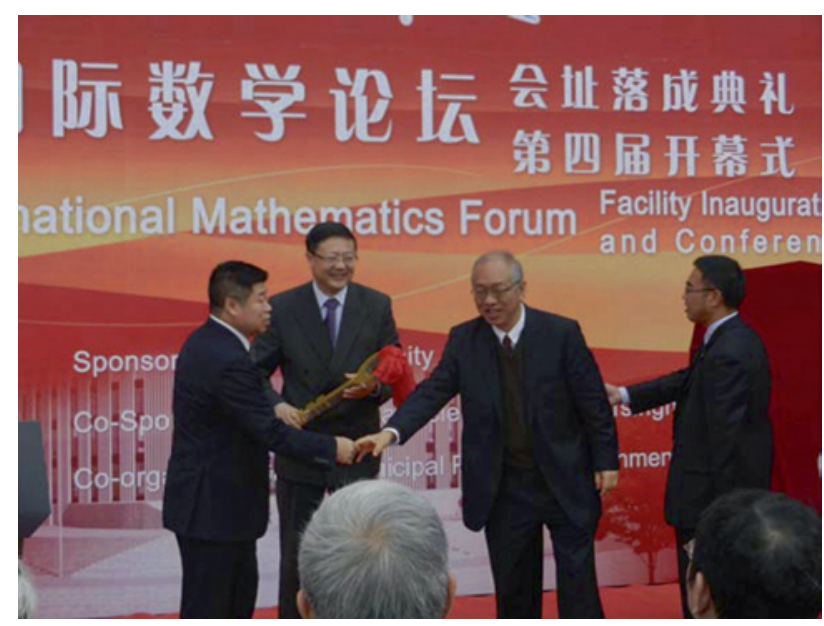

Figure 4. Prof. Yau with the President of Tsinghua University and the developer who built and donated the building.

\section{The Grand Opening of the Sanya Center}

The grand opening of the building was held at the top of the staircase. VIP included three Nobel laureates, three Fields medalists, two Wolf prize winners, and a Shaw prize laureate.

Prof. S. Y. Cheng chaired the opening ceremony, and Prof. Yang Lo congratulated the opening and success of the Sanya Forum. Prof. Yau expressed strongly the commitment of the Forum to the further development of mathematics of China and also of the world.

The president of Tsinghua University received a large key to the building from the developer who built and donated the buildings to the Forum, and he gave the key to Prof. Yau (Figs. 3, 4).

The opening and dedication of the building ended in a happy mood (Figs. 5, 6).

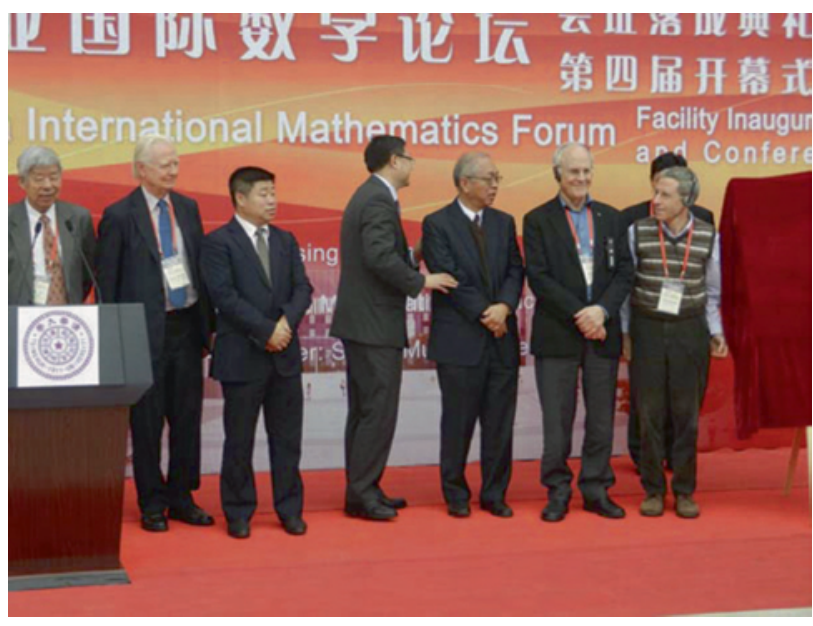

Figure 5. A group picture of Prof. Yau with three Nobel laureates and others.

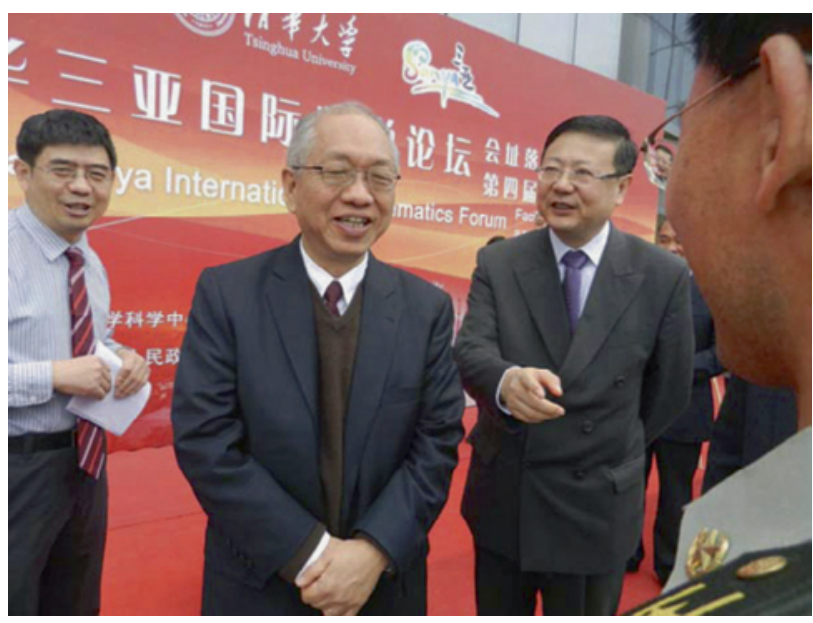

Figure 6. Prof. Yau with the President of Tsinghua University and the chairman of the math department of Tsinghua.

\section{A Tour at the Top}

Right after the grand opening, there was a tour to the top of the building. Standing there, one can view the South Sea. The ocean breeze and the warm sunshine made one wonder whether mathematics is beautiful or joyful.

Only two years ago, there was no road into the Phoenix mountain and there was nothing but trees on the top. Now a giant shinning building is standing there. One may wonder what thoughts went through Prof. Yau's mind at that moment.

Here is a picture of him enjoying the view from the top of the building with a big smile (Fig. 7).

Two Nobel laureates, Eric Maskin and James Mirrlees, were also in the tour group (Fig. 8). 


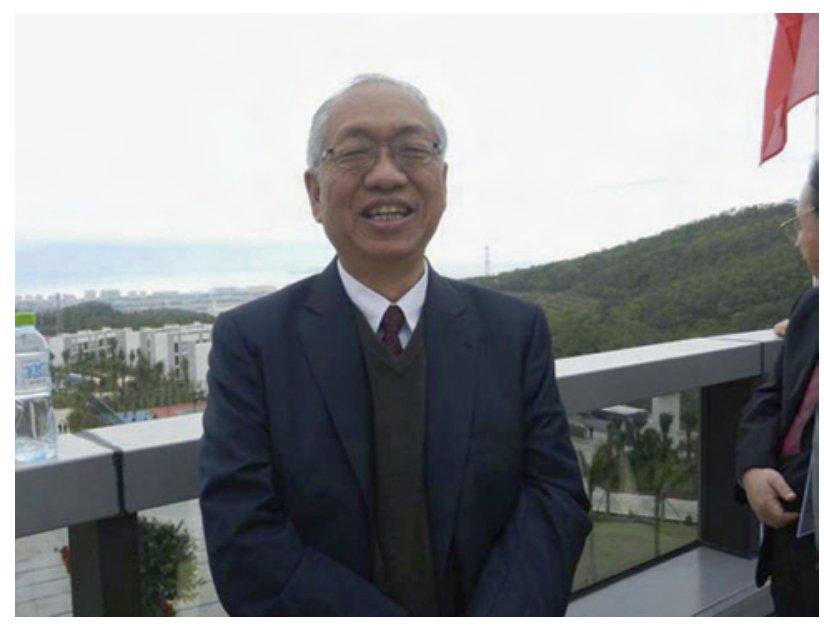

Figure 7. Prof. Yau on top of the main building.

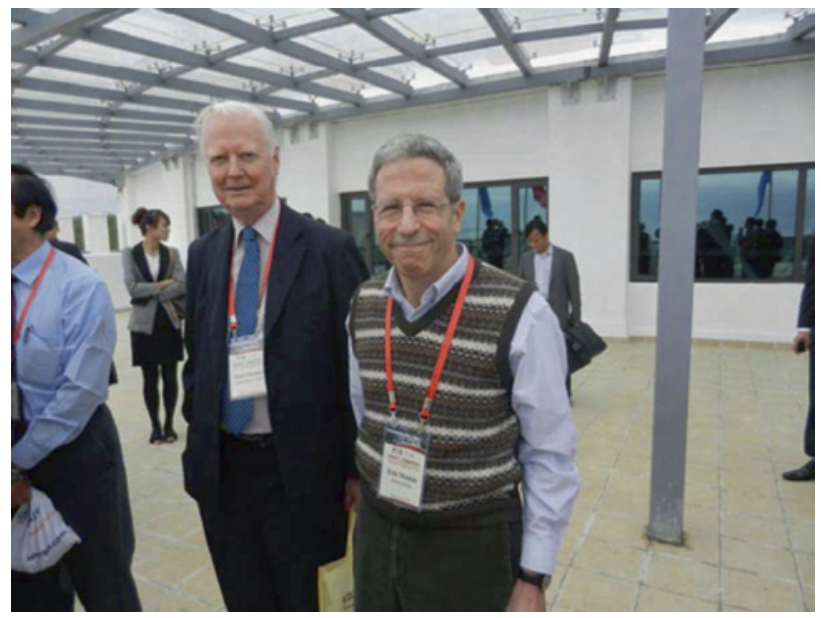

Figure 8. Nobel laureates, Eric Maskin and James Mirrlees, on top of the main building.

\section{A Chance Encounter with Nobel Laureates}

For me, one of the most special experiences is to have a chance to learn from some really smart people. I guess that this is the idea of the Sanya center: a paradise for scientific exchange at a tropical paradise!

There are many famous prizes and awards for scientists in the world. Probably everyone will agree that the most famous one is the Nobel prize. It is a pity that there is no Nobel prize in mathematics. Because of this, I have not had many chances to meet and talk to Nobel Laureates, probably the smartest among the smart people.

During the tour of the building after the grand opening, I was walking behind two Nobel Laureates in economics, Maskin and Mirrlees. I asked them whether group actions are used in their work (since I was writing a survey paper on group actions in all subjects). They said not really. Then I said how about symmetry. Yes, they replied, symmetry is used. It is

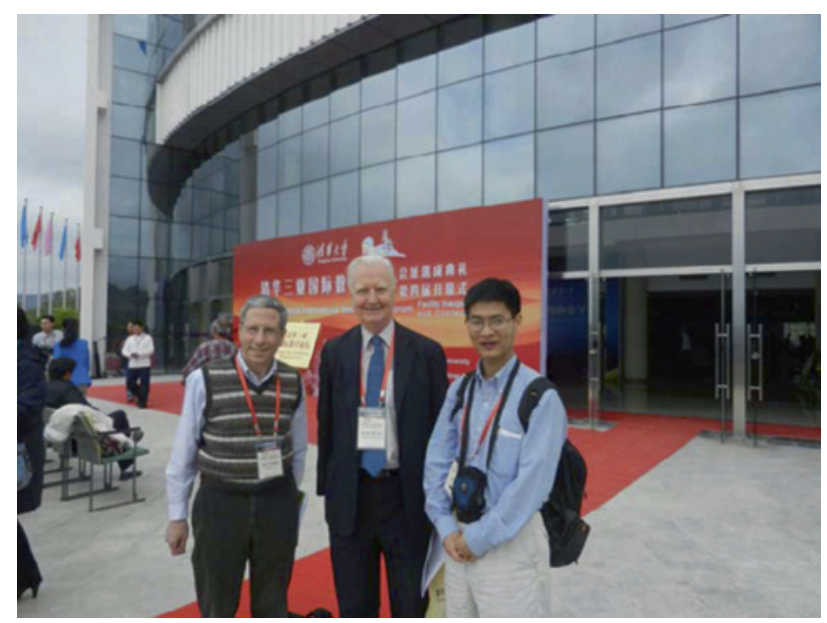

Figure 9. The author with Eric Maskin and James Mirrlees.

interesting that different names or perspectives make a difference.

Then I asked them what kind of mathematics is used in economics. They said that combinatorics and analysis are useful. Maskin also told me that he majored in mathematics when he was in college. In the last year, he attended a course by the famous economist Kenneth Arrow, a Nobel laureate, and switched to economics in graduate school and obtained a Ph. D. under Arrow. It is interesting to note that Maskin is one of the five students of Arrow who had gotten a Nobel prize. This should be a record in the history of the Nobel prize.

While we were standing on the first floor after the tour (Fig. 9), I decided to take this opportunity to ask some more challenging questions.

I remembered that Karl Marx's writing has had a huge influence on many countries and people, and students in China need to take many courses related to his theory on political economics. So I asked them if Marx was a good economist. Maskin replied that Marx was not a good economist but he was more a political thinker. I asked him if it is a good idea to read his famous book "Das Kapital". He said that if I wanted to learn something about economics, the classical book "The wealth of nations" by Adam Smith is still very readable and a good place to start.

Then I commented that several years ago when I took a walk on the main street in Edinburgh, the Royal Mile, I saw the statues of Adam Smith and of many other really famous and deep thinkers and scientists. That sight was probably more impressive than any other things I have ever seen. I said that it was always a mystery to me why so many brilliant people appeared at the same time, the age of enlightenment.

Maskin said that it was not really a mystery and the reason was that bright people interacted with 


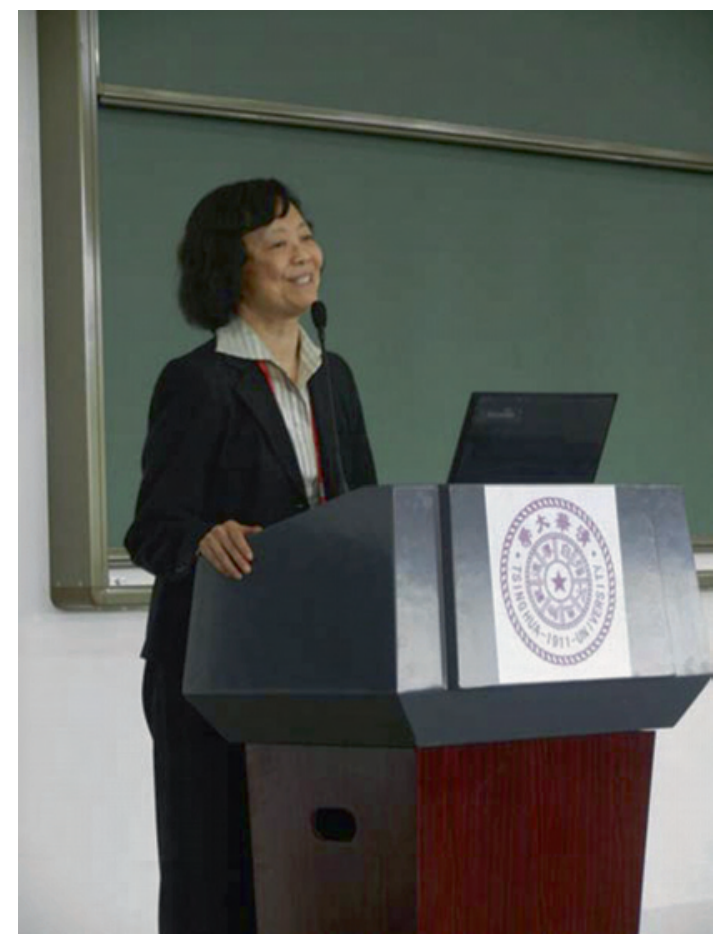

Figure 10. Winnie Li giving a speech.

and inspired other bright people so that they all became better. He also mentioned the example of $\mathrm{Vi}$ enna with many famous masters in music such as Haydn, Mozart, Beethoven and Schubert and emphasized the positive influence of these masters on each other.

Then I said that this is also the point of the new center in Sanya: people could get together and interact and hence influence with each other, and maybe he could mention this later at the conference.

I decided to ask a more daring question. There have been many economical disasters in the world, especially in USA, and people usually said that economists often (or almost always) made wrong predictions and were responsible for these disasters. So I asked them how they economists felt about the fact that they could not really predict the future of economics.

Maskin replied right away that like many other things such as weather, it is intrinsically difficult to predict; furthermore, as economists, their job was not to predict the future of economics but to understand the economics processes. Yes, it sounded like a sophisticated and good answer. Only later did I realize that if they could really understand economics processes, they should be able to predict the future better. (Otherwise, it is probably difficult to judge whether they have gained good understanding or not of economics processes). Several VIP gave speeches at the morning session on Dec. 18, 2013 (Fig. 10).

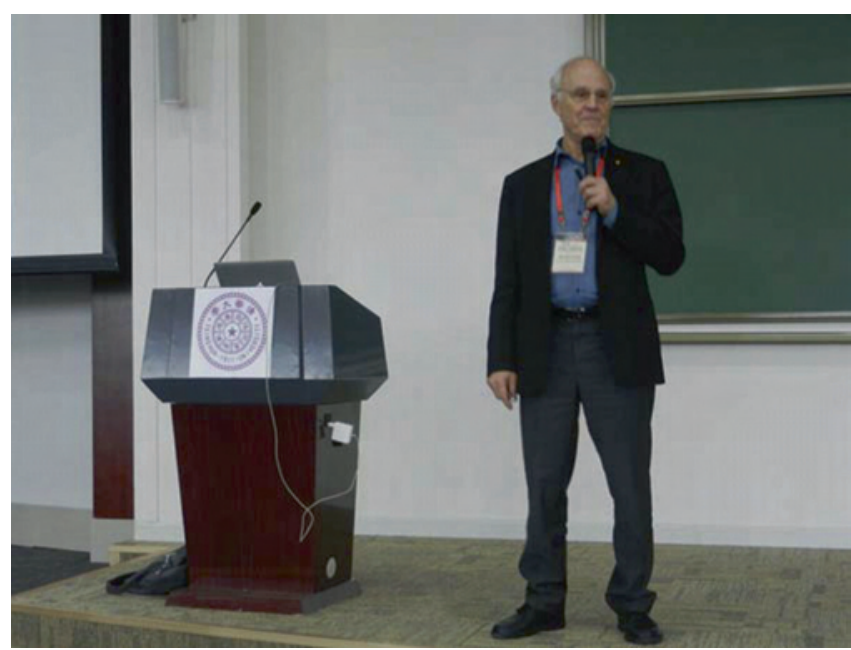

Figure 11. David Gross giving a speech.

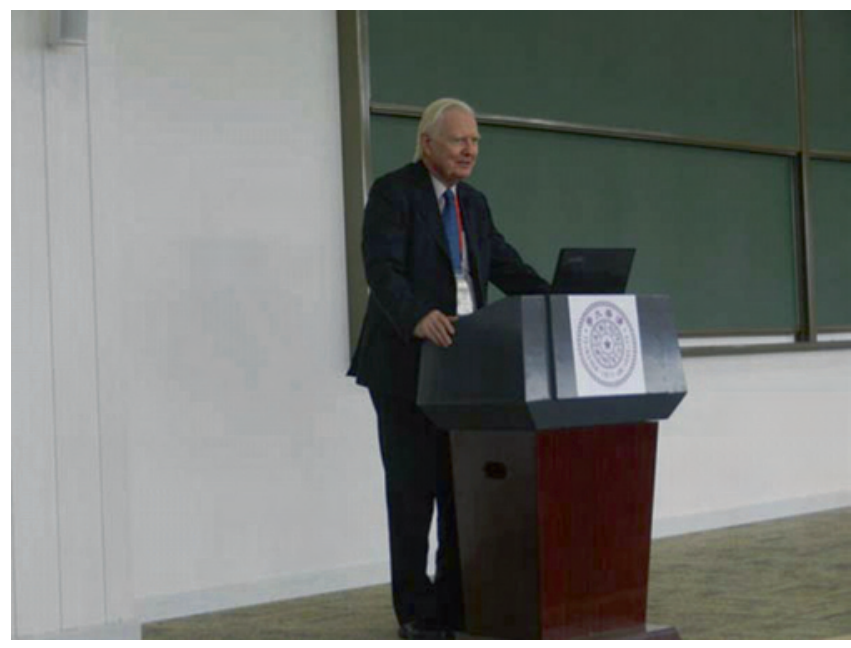

Figure 12. James Mirrlees giving his talk on rational choice.

Right after these speeches in the late morning, some distinguished speakers gave their talks aimed at the general audience. The Nobel laureate in physics David Gross started with a talk on the history of the grand unification (Fig. 11).

He is one of the smartest people I have ever met. I believe that he knew that he was really smart.

The second speaker was James Mirrlees who talked about rational choice. People often use the expression of rational choice (Fig. 12). But what is it exactly?

The third speaker was Eric Maskin about game theory through the example of the prisoner's dilemma (Fig. 13).

One interesting thing is that David Gross asked questions during the talks of the latter two Nobel laureates and seemed to startle or even embarrass them (Fig. 14). 


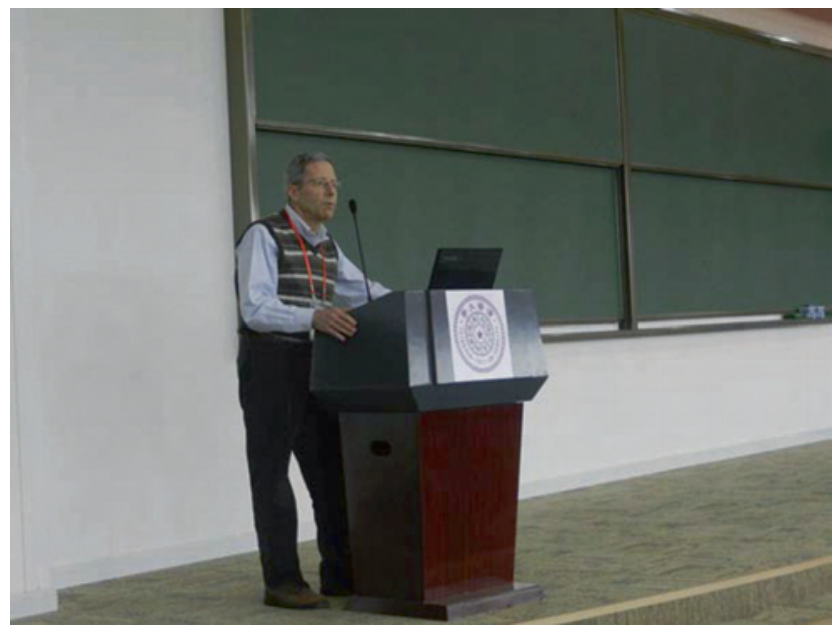

Figure 13. Eric Maskin giving his talk on game theory.

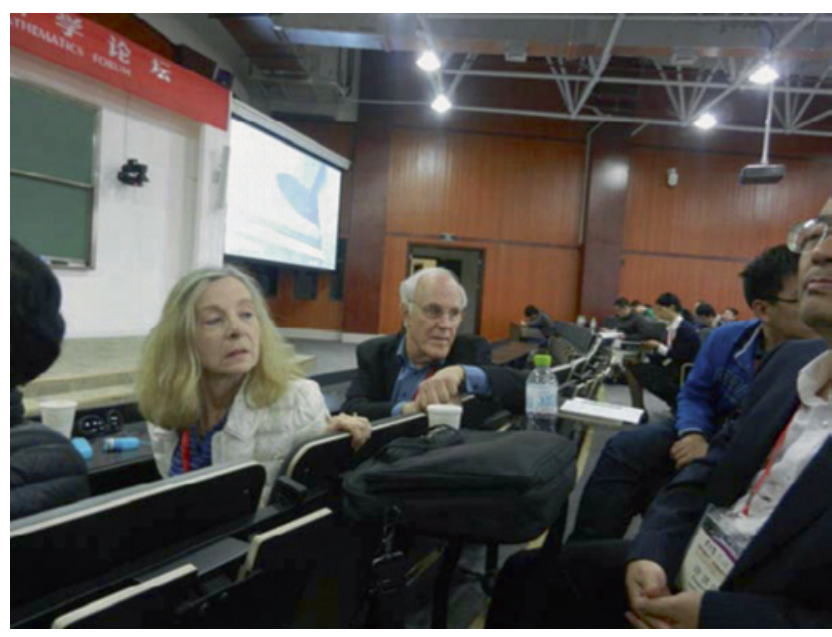

Figure 14. David Gross and his wife listening to Questions \& Answers.

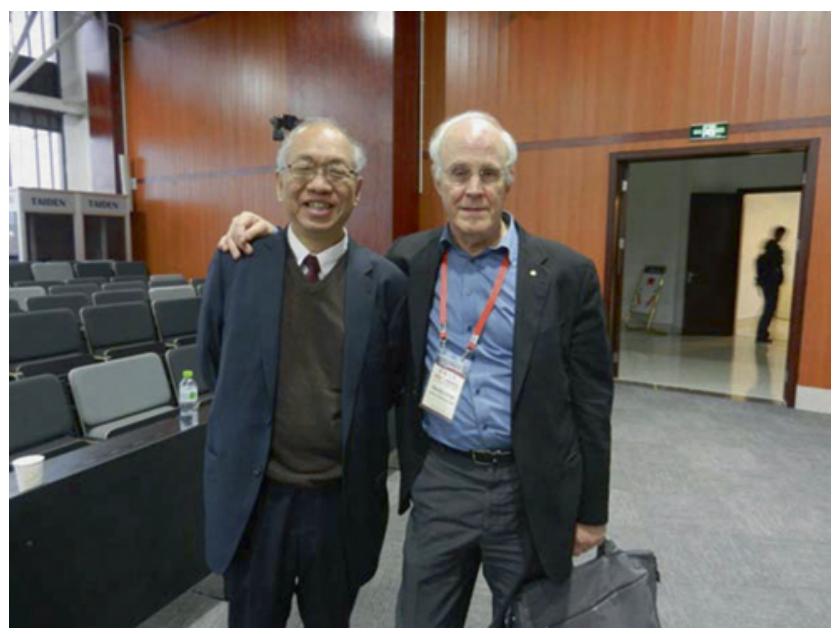

Figure 15. Prof. Yau and Prof. Gross laughing after the comments of Prof. Yau.

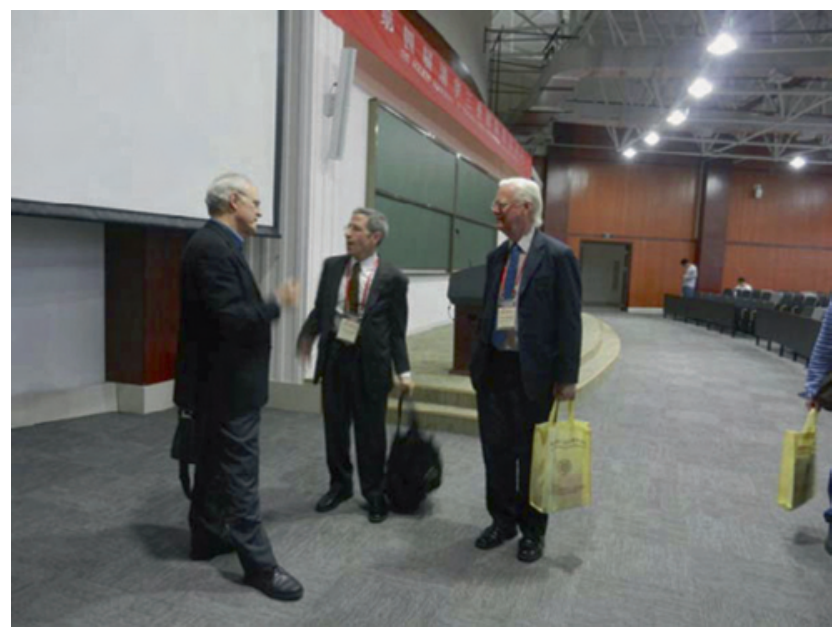

Figure 16. Three Nobel laureates continuing to discuss questions arising from Maskin's talk.

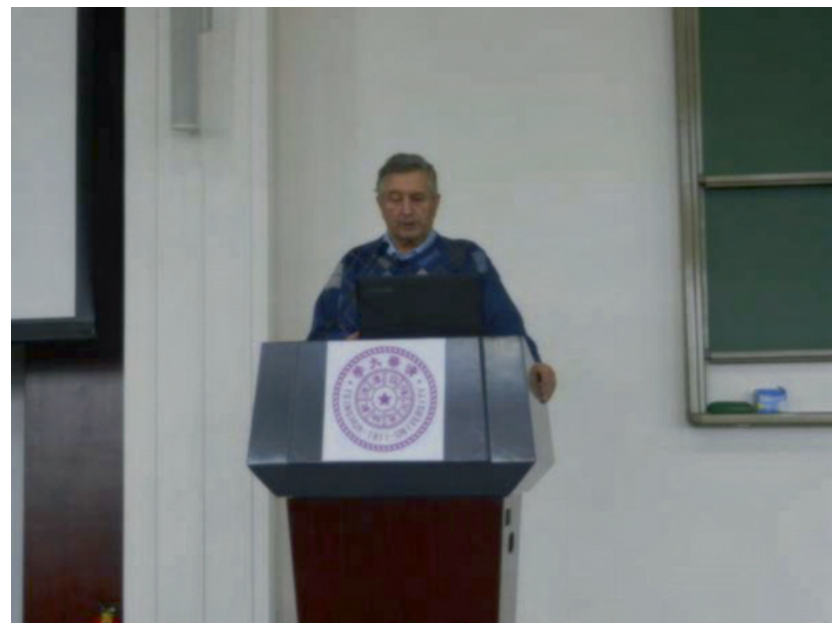

Figure 17. Yakov Sinai giving his Master lecture on mathematics.

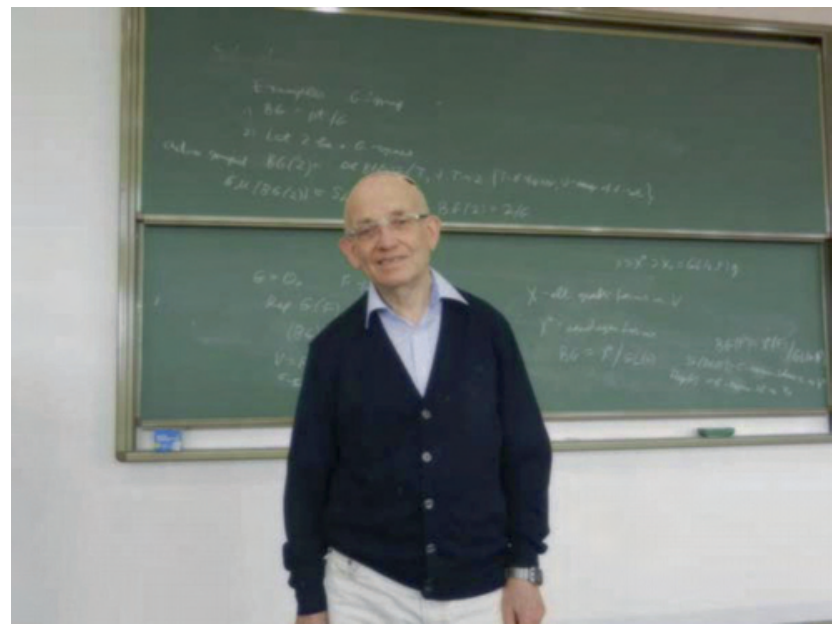

Figure 18. Joseph Bernstein giving his Master lecture on mathematics. 


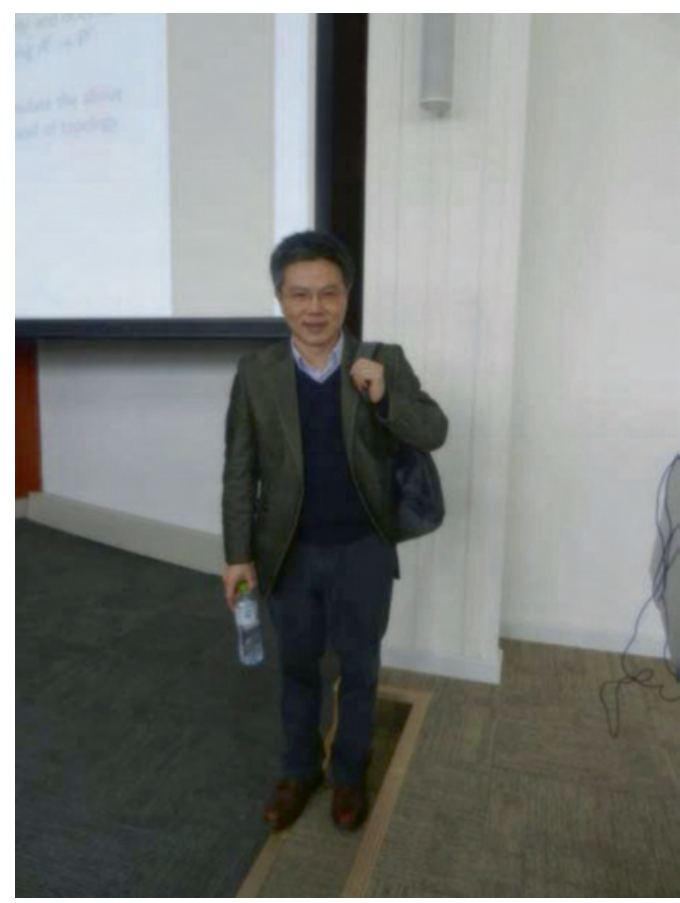

Figure 19. Bao-Chau Ngo giving his Master lecture on mathematics.

So I asked Gross how he could know so many things. He said happily and proudly, "by reading!". Prof. Yau overheard this and came and told me "Mathematicians and physicists often pretended that they know everything!" This made everyone laugh. So I took a picture of Yau and Gross laughing together (Fig. 15).

The three Nobel Laureates continued their discussion after others had left the room for the bus going down hill for lunch (Fig. 16).

\section{Master Lectures on Mathematics}

The grand opening of the Sanya center was followed by three days of Master Lectures on mathematics. The masters giving talks on mathematics were Sinai, Bernstein, Ngo and Taubes.

Here are pictures of them during the lectures (Figs. 17-20).

At this event, there are also some other famous people such as Stephen Smale.

On the excursion day, I sat next to him and asked him to give a summary of his own contributions to mathematics and he described clearly what he liked

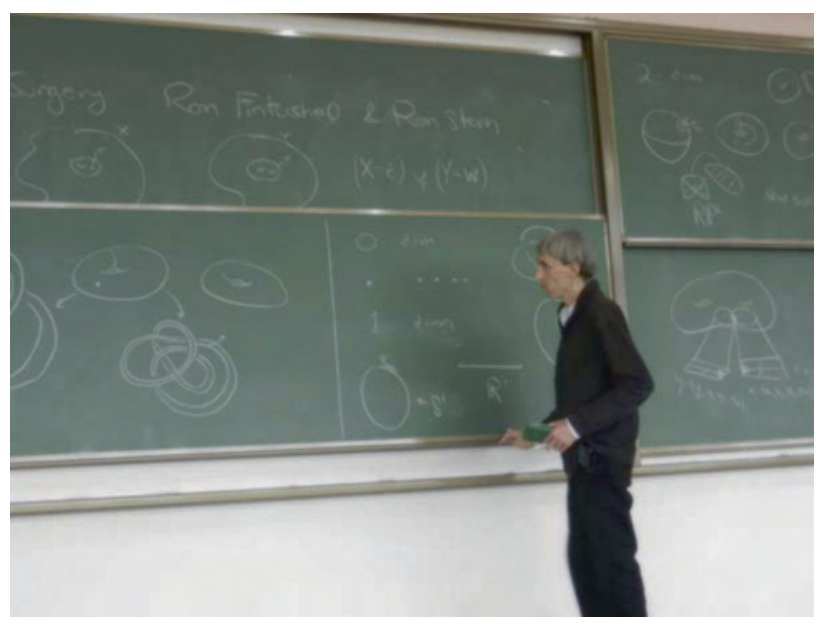

Figure 20. Clifford Taubes giving his Master lecture on mathematics.

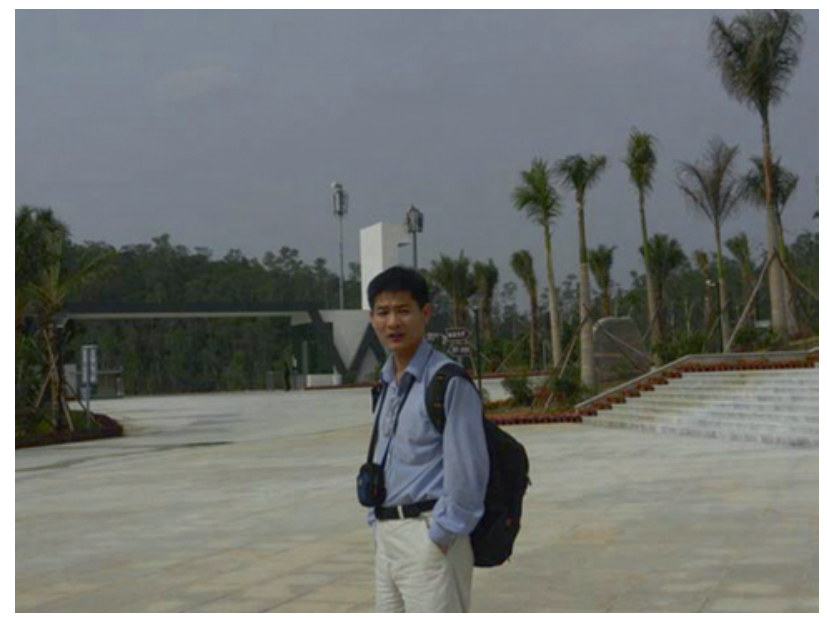

Figure 21. The author standing on the empty lot in front of the main building.

most among his mathematics. It would be interesting and instructive to have such a conversation with every living great mathematician. I also asked Taubes to comment on the works of some rather famous mathematicians, and this was also very educational.

After the conference ended, standing on the almost empty space in front of the steps, I wondered what the topics would be for the next meetings and next years (Fig. 21).

But one thing is clear. They will be exciting and good! 